\title{
An experimental study on response control of structures using multiple tuned liquid dampers under dynamic loading
}

\author{
Supradip Saha ${ }^{1} \cdot$ Rama Debbarma $^{1}$
}

Received: 25 May 2016/ Accepted: 2 December 2016/Published online: 24 December 2016

(C) The Author(s) 2016. This article is published with open access at Springerlink.com

\begin{abstract}
In this paper, the performance of multiple tuned liquid damper (MTLD) has been investigated in mitigating the response of a structure under dynamic loading, i.e., harmonic excitation. For comparative study, the responses of single-tuned liquid damper (STLD) have also been considered. A set of experiments are conducted on a scaled model of steel-structure-STLD and MTLD systems to evaluate the performance of the respective TLD models under harmonic excitation. Several excitation frequency ratios $(0.5-2.0)$ and depth ratios $(0.05-0.30)$ are considered for this study. The effect of resonance as well as tuned condition $\left(\omega_{d} / \omega_{s}=1\right)$ on the structural response has also been noticed. The effectiveness of the STLD and MTLDs is evaluated based on the response reduction of the structure. It has been found that the structural responses of displacement and acceleration are reduced significantly due to the installation of STLD and MTLD to the structure, respectively. Therefore, from this experimental study, it can be concluded that a TLD can successfully mitigate the response of the structure, but MTLD is not significantly more effective than an STLD when the liquid sloshing in the TLD is large.
\end{abstract}

Keywords Single-tuned liquid damper $\cdot$ Multiple tuned liquid damper - Vibration control - Excitation frequency ratio $\cdot$ Tuning ratio $\cdot$ Water-depth ratio

Supradip Saha

supradip.ce.str@gmail.com

Rama Debbarma

ramadebbarma@gmail.com

1 Department of Civil Engineering, National Institute of Technology Agartala, Barjala, Jirania,

Tripura (West) 799046, India

\section{Introduction}

In recent years, because of the shortage of land space accessibility, notably within the urban areas and also due to the implementation of modern technologies within the construction techniques have caused an increased presence of skyscraper structures. These skyscraper structures, as a result of this, have become relatively light in weight, flexible, and gently damped, typically resulting in little structural damping and low natural frequencies. They are quite efficient to carry transverse loads, but once they subjected to structural vibrations caused by the lateral loads (e.g., wind or earthquake), they undergo vital vibrations which may become unacceptable from the perspective of serviceability and safety. Over the past few decades, world has intimate with various devastating earthquakes, leading to enhanced loss of human life as a result of collapse of buildings and severe structural damages. Thus, to avoid such crucial damages, structural engineers are in operation to figure out different forms of structural systems that are robust and might withstand strong motions. As an alternative, some forms of structural protective systems can also be implemented to mitigate the damaging effects of these dynamic forces. These systems work either by absorbing or by reflecting some of the input energy, which may otherwise be transmitted to the structure itself.

In this present paper, the focus is on seismic response control with a passive vibration control device named tuned liquid damper (TLD) with single as well as multiple dampers. Advantages of TLD are greater compared with other passive vibration control devices, such as tuned mass dampers (TMDs), fluid viscous dampers, viscoelastic dampers, friction dampers, etc, because of its low cost, easy installation in the existing structure, easier handling, and few maintenance requirements. Since water is used as 
liquid in the TLD, it may be used for domestic purpose and as well as fire fighting. Basically, TMDs are the origin of the TLDs. A TLD is water confined in a container, usually placed on top of a building that uses the sloshing energy of the water to reduce the dynamic response of the system when it is subjected to excitation. It can more effective for absorbing low-frequency vibrations produced due to wind. The TLD tanks usually become small for several reasons; the space requirement; the need to tune its sloshing frequency to the natural frequency of the structure as well as to control the damping of liquid sloshing; and the lighter density of liquid in the TLD than that of steel, which is widely used as the mass in a TMD. Thus, the number of TLDs (tanks) installed in a structure ranges from several to a hundred or more to meet the required total mass of liquid.

The sloshing frequency of each individual TLD can be easily changed by varying in liquid depth. In a TLD, inherent liquid damping is rather small, at least in the range of sloshing with small amplitudes if other devices to create liquid damping are not used. It can be expected that a multiple TLD will possess a better performance when compared with a conventional TLD, where the same liquid depth is employed in all the TLDs. The conventional TLD is hereafter referred as Single TLD (STLD), since it has a single natural frequency.

Several studies have been made so far to elucidate the performance and effectiveness of TLDs. Among them, Fujino and Sun (1993) conducted numerical simulations as well as a set of experiments to evaluate the efficiency of MTLDs in the vibration control by varying the number of the TLD tanks that used in the MTLD-structure setup. Tamura et al. (1995) conducted a study to measure the efficiency of TLDs on reducing the wind excitations on tall structures. Banerji (2004) performed a series of experiments as well as numerical simulation to determine the behaviour of an SDOF structure attached with a TLD. Kim et al. (2006) investigated the characteristics of water sloshing motion in rectangular- and circular-shaped TLD as well as on TLCD by performing shake table experiments. Lee et al. (2007) experimentally determined the vibration control effect of a TLD through real-time hybrid shaking table testing method (RHSTTM) for a building structure exposed to earthquake load. Tait et al. (2008) investigated the performance of unidirectional and bidirectional tuned liquid damper TLDs under random excitation. Samanta and Banerji (2008) after conducting a numerical study proposed a new TLD configuration by introducing a rotating spring and rod to it in reducing the response of structures under harmonic base excitations. Roy and Ghosh (2012) carried out a study by frequency-domain method as well as performed a time-domain study to propose a TLD system for the response reduction of an elevated water tank. Bhattacharjee et al. (2013) investigated the performance of unidirectional single TLD to change the dynamic characteristics of the structure. Mondal et al. (2014) also verified experimentally the effectiveness of the TLD system and developed theoretical models for improving its performance. Bigdeli and Kim (2016) experimentally investigated the damping effect of three different types of passive vibration control devices, such as TMD, TLD, and TLCD on a scaled three-storey steel building structure. Ahmad et al. (2016) investigated the effectiveness of water tank as TLD for RC structures against earthquake vibrations through experimental study on two 4-storey RC frame structural models. Recently, Ruiz et al. (2016) proposed a tuned liquid damper with floating roof (TLD-FR) having a relatively simple, easy-to-model behaviour with high effectiveness in reducing the structural vibrations by introducing a floating roof in it, which prevents the water breaking.

The principle objective of this present study is to mitigate the response of the structure by means of installing a single-tuned liquid damper (STLD) and multiple tuned liquid damper (MTLD) model separately attached to the structure subjected to sinusoidal external motion as well as to evaluate the effect of different parameters, such as excitation frequency ratio and depth ratio etc on the performance of the STLD and MTLD.

\section{Theoretical formulation: equation of motion}

According to the linear theory, the fundamental sloshing frequency of a TLD, $f_{i}$, can be estimated using the following equation (Fujino and Sun 1993):

$f_{i}=\frac{1}{2 \pi} \sqrt{\frac{\pi g}{L_{D}} \tanh \frac{\pi h_{i}}{L_{D}}}$

where $g$ is the gravitational acceleration, $h$ is the still water depth in the tank, and $L_{D}$ is the length of the tank in the direction of the sloshing motion.

The frequency distributions of the MTLDs can be characterised by three quantities: the central frequency $f_{0}$, the frequency bandwidth $\Delta R$, and the frequency spacing $\beta_{i}$. They are expressed by

$f_{0}=\frac{f_{N}+f_{1}}{2}$

$\Delta R=\frac{f_{N}-f_{1}}{f_{0}}$

$\beta_{i}=f_{i+1}-f_{i}$

respectively, where $f_{i}$ is the natural sloshing frequency of the $i$ th individual TLD; $f_{1}$ and $f_{N}$ are the lowest and the highest $f_{i}$, respectively, and $N$ denotes the number of TLDs. To study the sensitivity of the MTLDs under an off-tuning situation, the off-tuning parameter $\Delta \gamma$ is defined as 
$\Delta \gamma=\frac{f_{s}-f_{0}}{f_{0}}$

where $f_{s}$ is the natural frequency of the structure. The individual TLD was designed to make the MTLDs having equal frequency spacing:

$\beta_{i}=\frac{f_{N}-f_{1}}{N-1}=\beta$.

The TLD with required $f_{i}$ was achieved by varying the liquid depth $h_{i}$. Since TLD tanks are of the same size used in MTLD, the mass and damping for each individual TLD are slightly different owing to the variation of the liquid depth.

The excitation frequency ratio $\left(\omega / \omega_{s}\right)$ is the ratio of the excitation frequency to the structural natural frequency $\left(\omega_{s}\right)$ which is controlled by varying external frequencies. The tuning ratio $(\gamma)$ is the ratio of the natural frequency of the damper $\left(\omega_{d}\right)$ to the natural frequency of the structure $\left(\omega_{s}\right)$. The depth ratio $(\Delta)$ of the damper is the ratio of the height of the water in the damper $(H)$ to the effective length of the damper $\left(L_{D}\right)$ in the direction of motion.

\section{Experimental setup}

The arrangement of the steel-structure model over the shake table along with the STLD and MTLD model is shown in Figs. 1 and 2, respectively.

Various specifications related to the shake table used for the experiment are listed in the following:

The shake table, which is unidirectional in nature, will impose horizontal motion to the structure. The size of the shake table used for the experiments is $1 \mathrm{~m} \times 1 \mathrm{~m}$. The self-weight of the shake table is $100 \mathrm{~kg}$ (approximately). The range of maximum displacement is limited to $\pm 100 \mathrm{~mm}$. The maximum operating frequency that can be applied to the shake table is in between 0 and $10 \mathrm{~Hz}$, and the device which is required for applying the desired

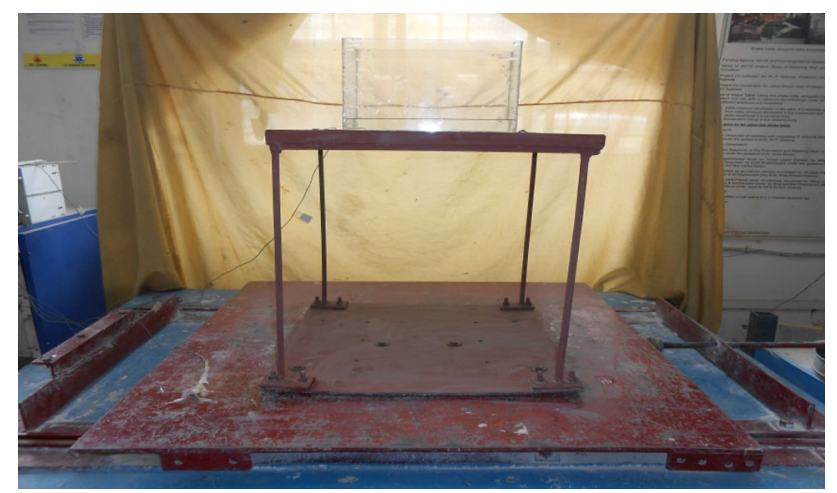

Fig. 1 Experimental setup of STLD-structure system

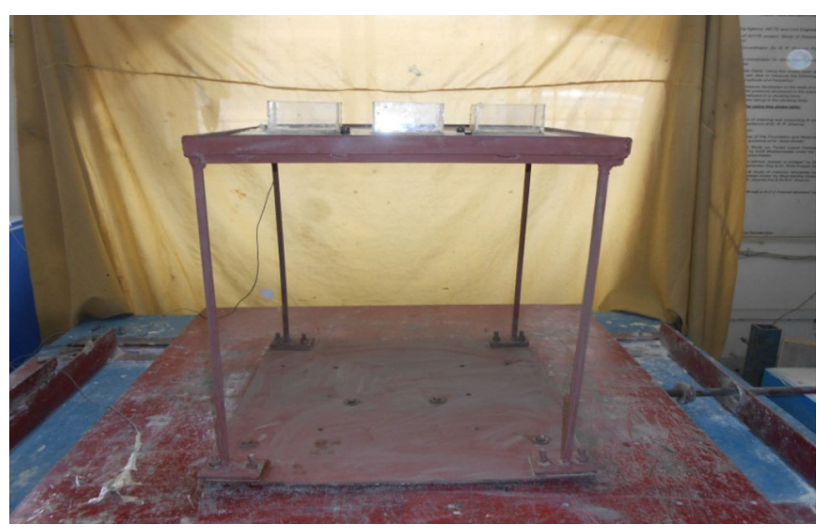

Fig. 2 Experimental setup of MTLD-structure system

operating frequency is microprocessor-based three-phase precision AC drive.

Various specifications of the SDOF steel-structure model:

The steel-structure model has a mild steel plate of thickness $10 \mathrm{~mm}$, so that it acts as a rigid slab of a structure. The load of the slab is transferred first into the beams then into the columns. There are four numbers of beams and columns of size $10 \mathrm{~mm} \times 10 \mathrm{~mm} \times 500 \mathrm{~mm}$. The columns are connected to beams and the slab and the base plate by welding. The natural frequency $\left(f_{s}\right)$ of the steelstructure model is $1.229 \mathrm{~Hz}(7.7 \mathrm{rad} / \mathrm{s})$, while the fundamental time period $(T)$ is $0.808 \mathrm{~s}$.

Various specifications of the single TLD water tank experimental case:

The STLD model is made up of glass fibre sheet of $2 \mathrm{~mm}$ thickness. It resembles a rectangular-shaped water tank. The fundamental frequency of this conventional TLD system is $7.7 \mathrm{rad} / \mathrm{s}$, and the water depth is maintained relatively. The instrument used in the experiments conducted on the STLD model is Brüel \& Kjær Deltatron 4507-01 accelerometer placed at the top and bottom of the structure.

Various specifications of the multiple TLD experimental case:

The multiple TLD water tanks are made up of glass fibre sheet of $2 \mathrm{~mm}$ thickness. It basically resembles of smaller rectangular-shaped water tanks when compared with that of single TLD model. The number of tanks used for this experimental study is three (3). The MTLDs used in this study are of the same size having the same length " $\mathrm{L}_{\mathrm{D}}$ " as $10 \mathrm{~cm}$ and width " $\mathrm{B}_{\mathrm{D}}$ " as $5 \mathrm{~cm}$. The instruments used for measuring the responses of MTLD experiments are as the same as the earlier STLD experimental case.

Some more essential parameters regarding MTLD experiment are listed in the following:

The three numbers of TLD tanks have a frequency bandwidth $(\Delta R)$ of 0.2 , off-tuning factor $(\Delta \gamma)$ equals to 0 
and frequency spacing $\left(\beta_{i}\right)$ of 0.77 . The central frequency $\left(f_{0}\right)$ of the MTLDs, i.e., the natural frequency of the centrally placed TLD tank, is $7.7 \mathrm{rad} / \mathrm{s}$, which is tuned to that the fundamental frequency of steel structure.

The MTLDs are distributed in the frequency range of $0.90 \leq \frac{f_{i}}{f_{o}} \leq 1.10$.

Therefore, the natural frequency of the TLD tank located nearest to the forcing element $f_{2}$ is equal to $8.47 \mathrm{rad} / \mathrm{s}$ and for the tank placed farthest from the forcing element $f_{1}$ is equal to $6.93 \mathrm{rad} / \mathrm{s}$.

The motion imposed on the structure is harmonic in nature, with control over the frequency of the oscillations. The measured response parameters are acceleration and displacement of the structure along the line of action of the force. In case of the STLD-structure system and MTLDstructure system, the acceleration and displacement responses are measured by attaching Brüel \& Kjær Deltatron 4507-01 accelerometers (Brüel and Kjær Sound and Vibration Measurement A/S, Nærum, Denmark) at the base and top of the structure model. PULSE 3560B computerised data acquisition and multi-analyser system are used to acquire and analyse the data obtained in the experiments. In each set of the experiment, the damper-structure system is subjected to harmonic sinusoidal base motions. This external motion imposed to the structure by means of an induction motor mounted on the shake table. To maintain this external excitation amplitude constant, the displacement of the shake table has been kept constant. The detailed specifications of the STLD and MTLD models are shown in Tables 1 and 2 respectively. The Table 3 represents the various parameters of the STLD and MTLD experimental cases.

\section{Selection of STLD and MTLD parameters}

The response of the steel-structure model attached separately with STLD and MTLD and subjected to a base excitation will mainly depend on the characteristics of the STLD-structure system and MTLD-structure system. A damper (STLD or MTLD) may be considered as properly designed if it reduces the structure's motion for a particular base excitation for a given set of values of excitation frequency ratios $\left(\omega / \omega_{s}\right)$, several water-depth ratios $(\Delta)$, etc of
Table 2 Details of MTLD parameters

\begin{tabular}{lllllll}
\hline Model type & Shape of MTLD & \multicolumn{5}{l}{ MTLD frequencies in rad/s } \\
\cline { 3 - 7 } & & $N$ & $f_{1}$ & $f_{\mathrm{o}}$ & $f_{2}$ & $f_{s}$ \\
\hline MTLD & Rectangular & 3 & 6.93 & 7.7 & 8.47 & 7.7 \\
\hline
\end{tabular}

the liquid present in the tank. To avoid the non-linear effects of the liquid motion, small external harmonic force has been used in this experiment.

\section{Results and discussions}

Investigations are conducted to study the dynamic behaviour of the structure with STLD and with MTLD when it is subjected to harmonic base motion applied to the shake table. The harmonic ground motion is defined by its excitation frequency and amplitude ground motion. In this present study, displacement and acceleration of the structure with and without the damping system (STLD/MTLD) are measured by attaching Brüel \& Kjær Deltatron 4507-01 accelerometers and PULSE 3560B computerised data acquisition system, considering different excitation frequency ratios and water-depth ratios. The experimental data related to the structural responses without any damping system are considered from Saha and Debbarma (2015). The results obtained from this experimental study have been discussed and compared thereafter.

\section{Effect of various external frequencies on structural response}

The variations of displacement of structure with various excitation frequency ratios for different water-depth ratios using STLD and MTLD are shown in Figs. 3 and 4. Various external excitation frequency ratios ranging from 0.5 to 2.0 are also considered in this experimental study, and the corresponding structural response has been observed. It is observed that the displacement of structure reduces using STLD and MTLD compared with that of without any damper. It is also observed that displacement decreases with the increase in the water-depth ratio. Furthermore, it can be seen that the peak
Table 1 Details of STLD parameters

\begin{tabular}{lllll}
\hline Model type & Shape of TLD & \multicolumn{3}{l}{ STLD dimensions } \\
\cline { 3 - 5 } & & Length $\left(L_{D}\right)$ in $\mathrm{cm}$ & Width $\left(B_{D}\right)$ in cm & Depth $(H)$ in cm \\
\hline STLD & Rectangular & 30 & 15 & 20 \\
\hline
\end{tabular}


Table 3 STLD and MTLD experimental cases

\begin{tabular}{llll}
\hline Model & Water-depth ratio $(\Delta)$ & External frequency in $\mathrm{Hz}$ & External frequency ratio $\left(\omega / \omega_{s}\right)$ \\
\hline STLD & $0.05,0.10,0.15,0.20,0.25,0.30$ & $0.613,0.919,1.229,1.532,1.839,2.146,2.45$ & $0.5,0.75,1.0,1.25,1.50,1.75,2.0$ \\
MTLD & $0.05,0.10,0.15,0.20,0.25,0.30$ & $0.613,0.919,1.229,1.532,1.839,2.146,2.45$ & $0.5,0.75,1.0,1.25,1.50,1.75,2.0$
\end{tabular}

Fig. 3 Variation of displacement of structure with various excitation frequency ratios for STLD considering various water-depth ratios ranging from 0.05 to 0.30

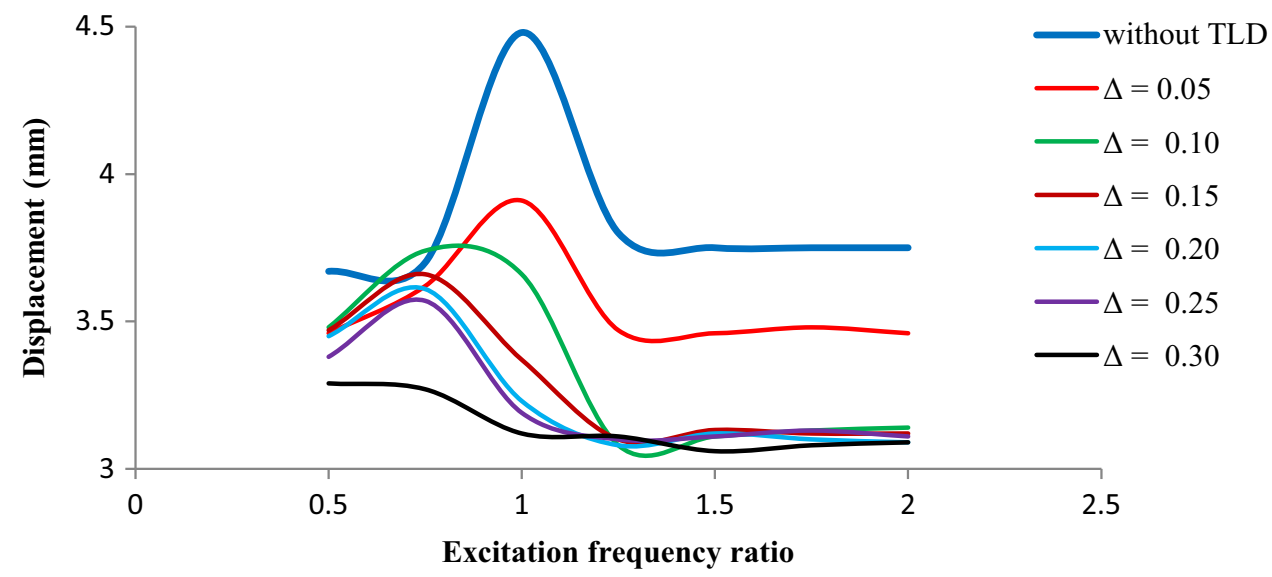

Fig. 4 Variation of displacement of structure with various excitation frequency ratios for MTLD considering various water-depth ratios ranging from 0.05 to 0.30

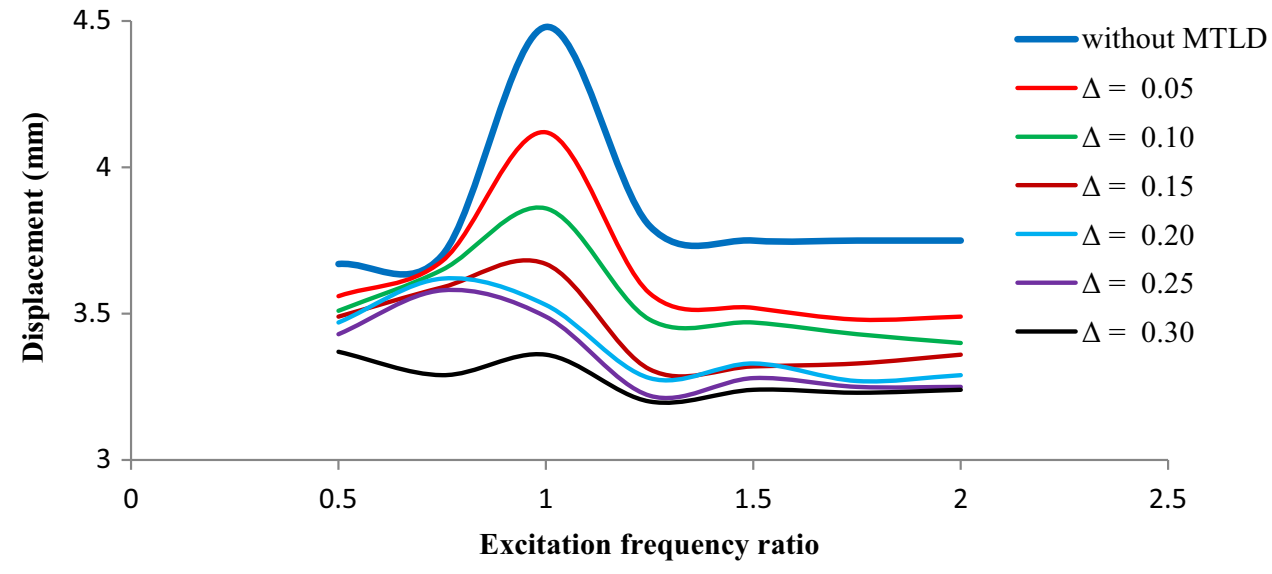

structural responses are occurred at the resonant frequency. At lower water-depth ratios, the effectiveness of MTLD is more when compared the response reduction to that of STLD. However, at higher water-depth ratios, due to higher liquid sloshing phenomena in the STLD compared with the other one, STLD is more effective. Similar trends of curves can also be observed for the acceleration of the structure model fitted with STLD and MTLD model in Figs. 5 and 6.

\section{Variation of structural responses with time histories}

The variations in the displacement time histories at top of the scaled steel-structure model are plotted in Figs. 7 and 8; meanwhile, the acceleration time histories are shown in Figs. 9 and 10 for STLD and MTLD systems, respectively. These experiments are conducted considering that excitation frequency ratio $\left(\omega / \omega_{s}\right)$ is equal to 1 , tuning ratio $(\gamma)$ is equal to 1 , and for varying water-depth ratios. The variation of water-depth ratio is from 0.05 to 0.3 for the STLD experimental case, while for MTLD case, it is $0.1-0.3$. The water-depth ratio which is considered for the MTLD experimental case is basically for the centrally placed water tank. The water-depth ratios for the other tanks are accordingly adjusted using the frequency distribution relation between the water tanks. It can be easily observed that with the implementation of STLD and MTLD model in the structure, the structural responses get reduced. In addition, if the water-depth ratio gets increased, the responses get reduce simultaneously in both cases. 
Fig. 5 Variation of acceleration of structure with various excitation frequency ratios for STLD considering various water-depth ratios ranging from 0.05 to 0.30

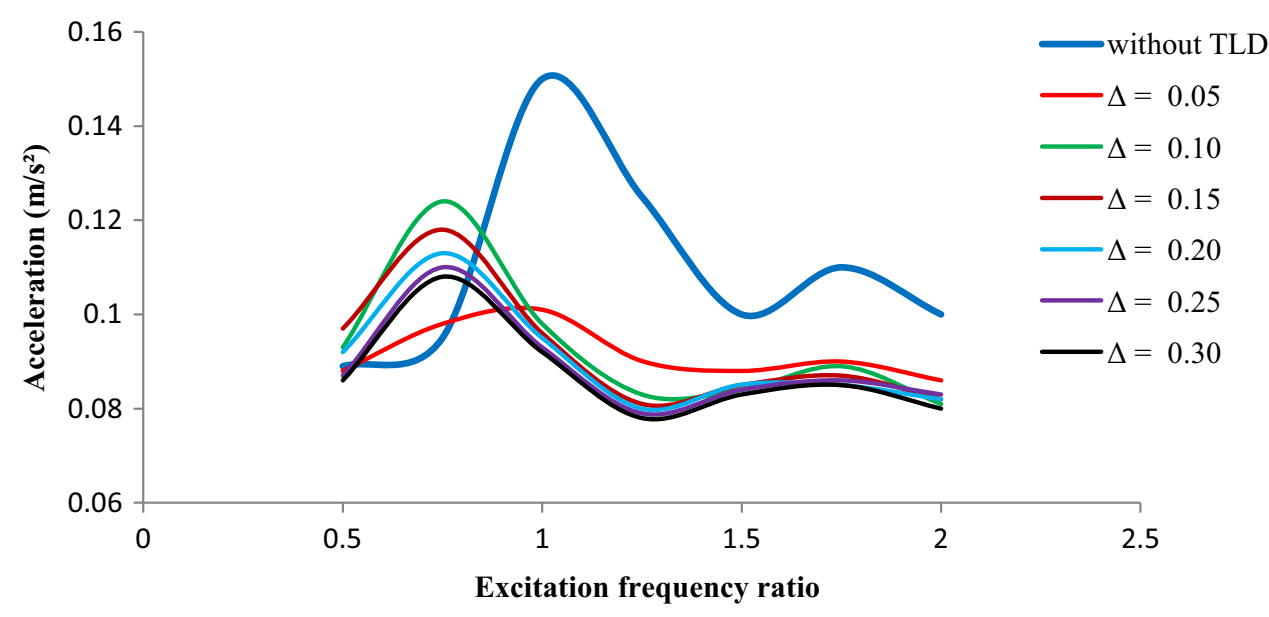

Fig. 6 Variation of acceleration of structure with various excitation frequency ratios for MTLD considering various water-depth ratios ranging from 0.05 to 0.30
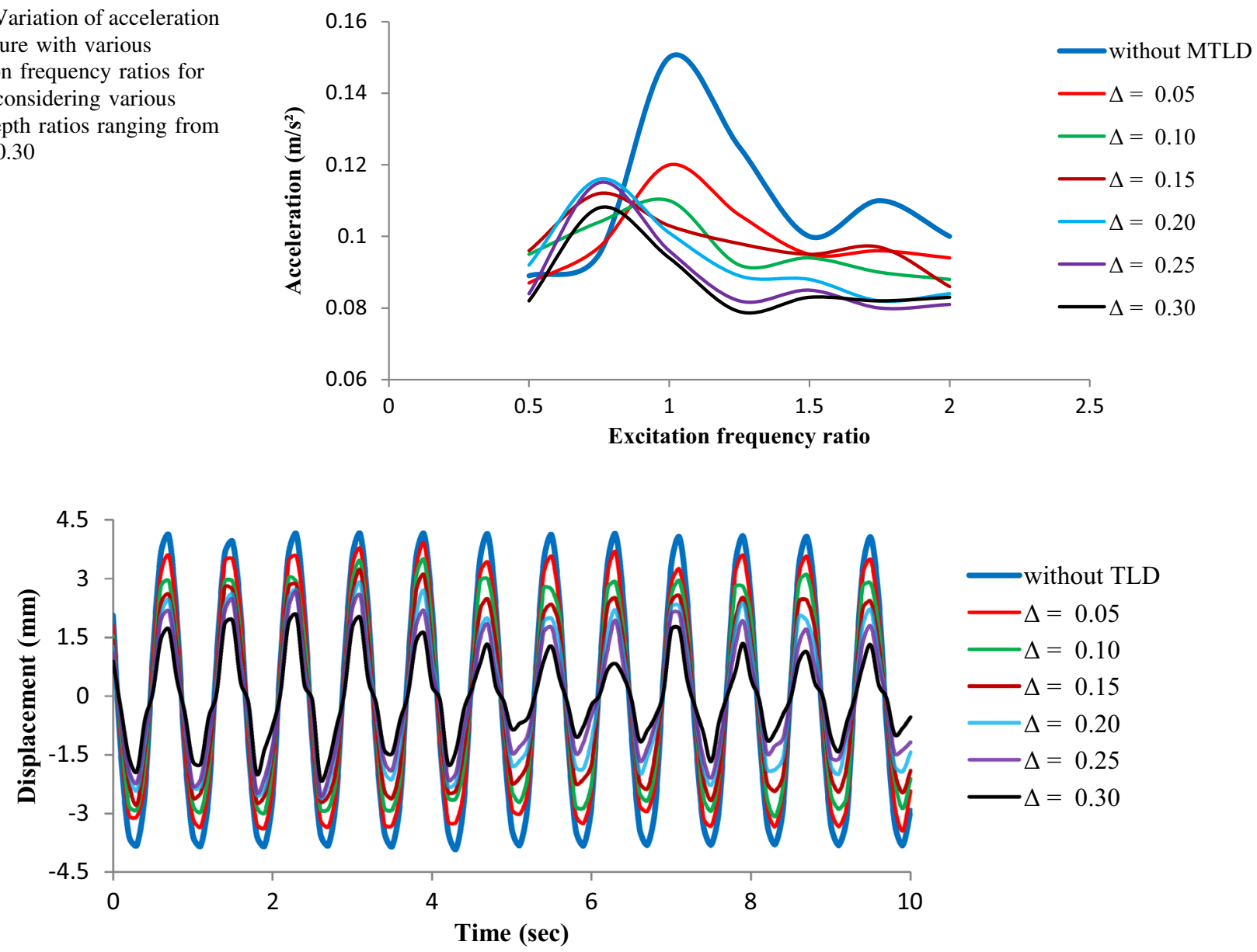

Fig. 7 Variation of displacement of structure with time (with and without STLD) for various water-depth ratios from 0.05 to 0.30 , considering excitation frequency ratio $\omega / \omega_{s}=1$ and tuning ratio $\gamma=1$

\section{Effectiveness of the dampers}

The effectiveness of the STLD ( $\left.\psi_{\text {STLD }}\right)$ and MTLD $\left(\psi_{\text {MTLD }}\right)$ is calculated in terms of the reduction of structural displacement or acceleration with STLD and MTLD compared with the corresponding value without any damper (STLD and MTLD), respectively:

$\psi_{\mathrm{STLD}}=\left(\frac{x_{s}-x_{\mathrm{STLD}}}{x_{s}}\right) \times 100 \%$ 


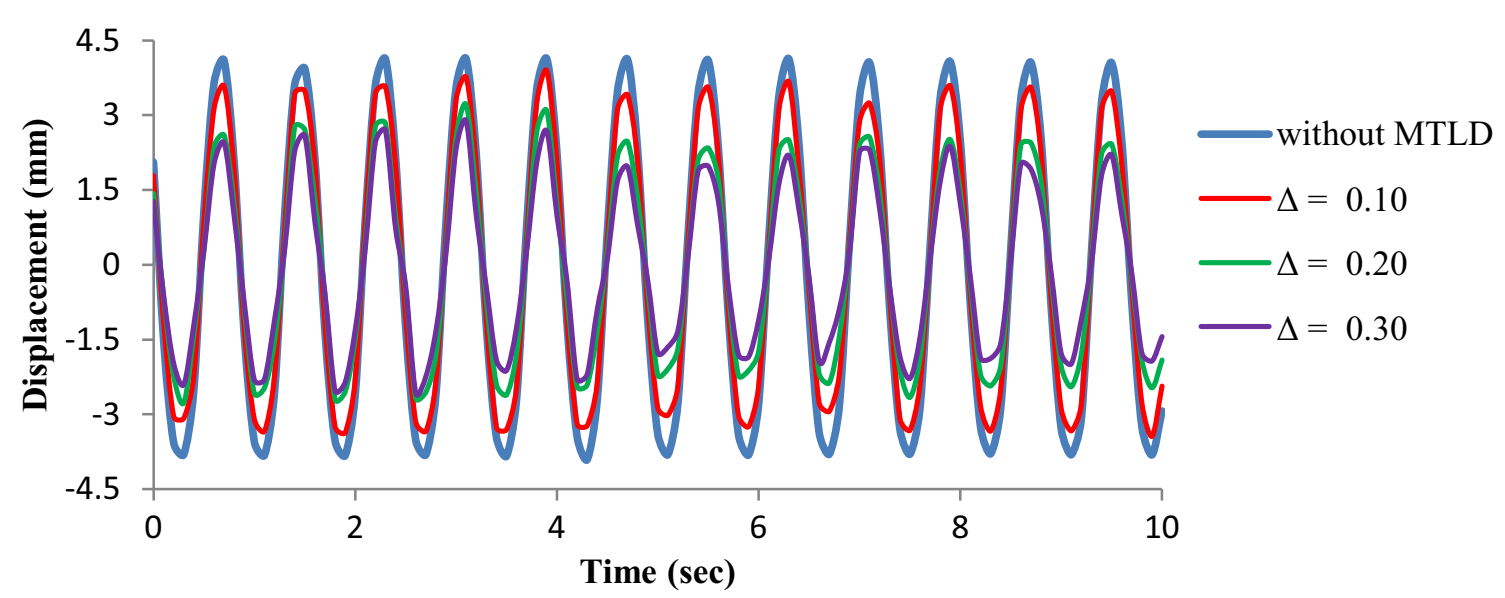

Fig. 8 Variation of displacement of structure with time (with and without MTLD) for various water-depth ratios varying from 0.10 to 0.30 , considering excitation frequency ratio $\omega / \omega_{s}=1$ and tuning ratio $\gamma=1$

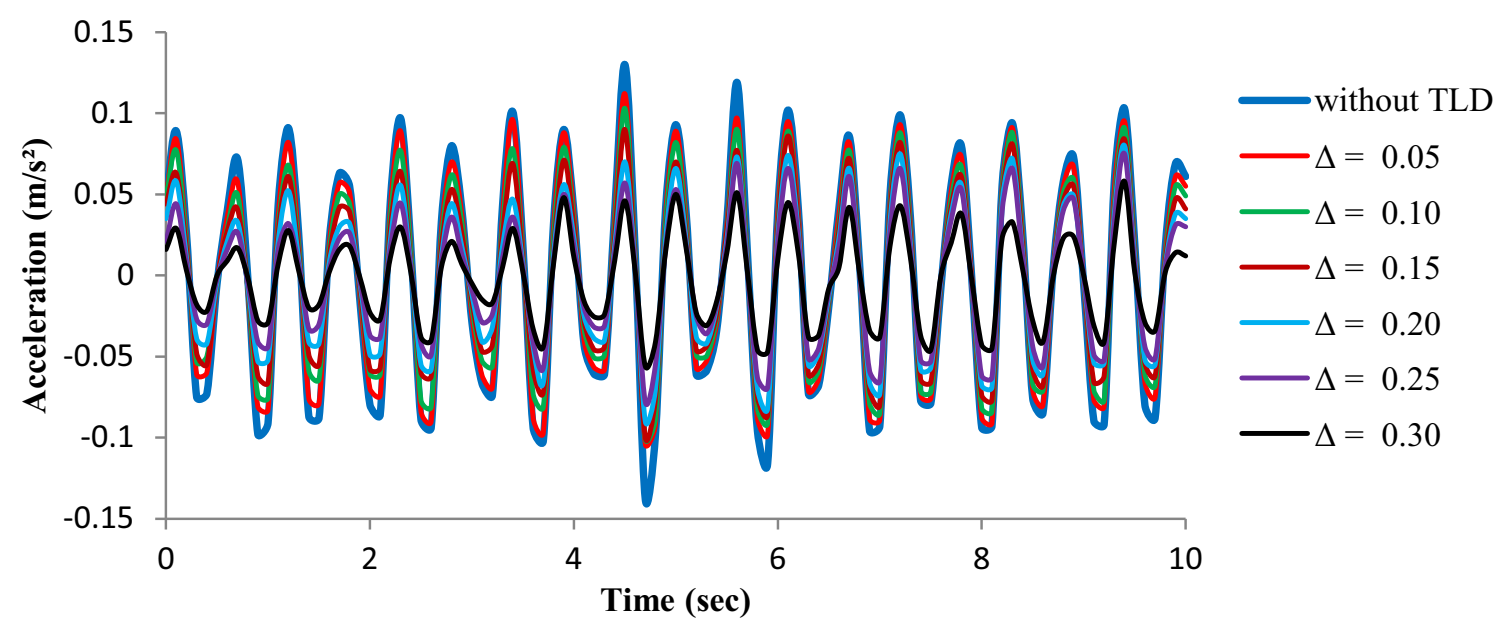

Fig. 9 Variation of acceleration of structure with time (with and without STLD) for various water-depth ratio from 0.05 to 0.30 , considering excitation frequency ratio $\omega / \omega_{s}=1$ and tuning ratio $\gamma=1$

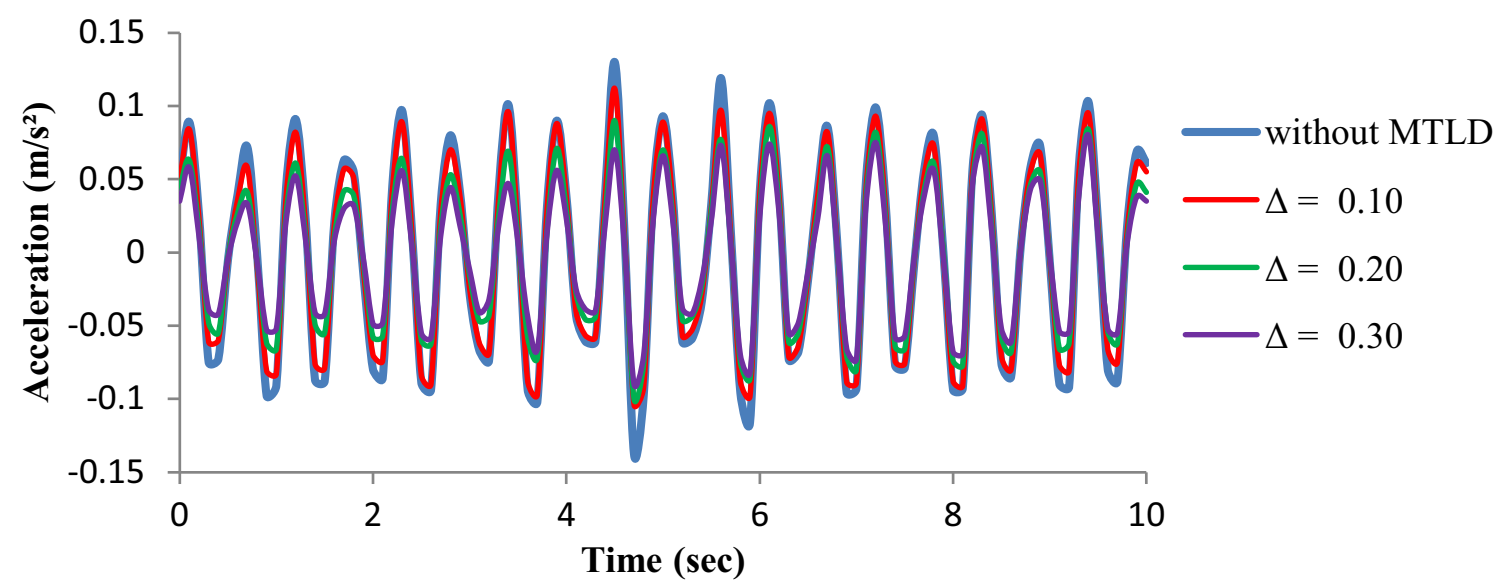

Fig. 10 Variation of acceleration of structure with time (with and without MTLD) for various water-depth ratio varying from 0.10 to 0.30, considering excitation frequency ratio $\omega / \omega_{s}=1$ and tuning ratio $\gamma=1$ 
Table 4 Displacement reduction of structure

\begin{tabular}{llllllc}
\hline Water-depth ratio $(\Delta)$ & \multicolumn{2}{l}{ Displacement $(\mathrm{mm})$} & & \multicolumn{2}{l}{ Response reduction $(\%)$} \\
\cline { 2 - 3 } & Without structure & STLD & MTLD & & STLD & MTLD \\
\hline 0.10 & 4.5 & 2.47 & 2.36 & & 45.11 & 47.56 \\
0.20 & 4.5 & 1.82 & 1.97 & & 59.56 & 56.22 \\
0.30 & 4.5 & 1.31 & 1.58 & & 70.89 & 64.89 \\
\hline
\end{tabular}

Table 5 Acceleration reduction of structure

\begin{tabular}{llllllc}
\hline Water-depth ratio $(\Delta)$ & \multicolumn{2}{l}{ Acceleration $\left(\mathrm{m} / \mathrm{s}^{2}\right)$} & & \multicolumn{2}{l}{ Response reduction $(\%)$} \\
\cline { 2 - 3 } & Without structure & STLD & MTLD & & STLD & MTLD \\
\hline 0.10 & 0.15 & 0.103 & 0.090 & 31.33 & 40.00 \\
0.20 & 0.15 & 0.070 & 0.078 & & 53.33 & 48.00 \\
0.30 & 0.15 & 0.046 & 0.052 & & 69.33 & 65.33 \\
\hline
\end{tabular}

$\psi_{\mathrm{MTLD}}=\left(\frac{x_{s}-x_{\mathrm{MTLD}}}{x_{s}}\right) \times 100 \%$

where $x_{s}, x_{\mathrm{STLD}}$, and $x_{\mathrm{MTLD}}$ are the peak displacement or acceleration values of without and with STLD and MTLD, respectively.

The comparative study of the response reduction due to the installation of STLD and MTLD of the structural responses is also demonstrated in Tables 4 and 5, given in the following section, for displacement and acceleration, respectively, measured at the top of the structure. These observations have been made for tuning ratio equals to unity.

\section{Conclusions}

The present study focused on the mitigation of structural responses by implementing of multiple tuned liquid damper (MTLD) on a scaled structure and also with a singletuned liquid damper (STLD), having a single natural frequency. A set of experiments are carried out for studying the behaviour of the STLD and MTLD under harmonic loading. These damper systems are separately mounted over the steel-structure model, and a set of experiments are performed for studying the behaviour of the respective damper system. Several excitation frequency ratios varying from 0.5 to 2.0 and various water-depth ratios varying from 0.05 to 0.30 were considered. The effect of resonance as well as tuned condition $\left(\omega_{d} / \omega_{s}=1\right)$ on the structural response has also been noticed. From the obtained results, it has been observed that, at the resonance frequency, the peak structural response occurs and maximum response reduction also occurs at the resonance condition for STLD and MTLD systems. The effectiveness of the conventional TLD and multiple TLD water tanks measured according to their structural response reduction ability. In addition, it can be observed that at lower water-depth ratios, the response reduction by the MTLD is more compared with that of STLD, but effectiveness of STLD system is more at higher water-depth ratios. Therefore, it can be concluded that a TLD system can successfully mitigate the response of the structure, but MTLD is significantly more effective than an STLD within a small amplitude range.

Open Access This article is distributed under the terms of the Creative Commons Attribution 4.0 International License (http://creative commons.org/licenses/by/4.0/), which permits unrestricted use, distribution, and reproduction in any medium, provided you give appropriate credit to the original author(s) and the source, provide a link to the Creative Commons license, and indicate if changes were made.

\section{References}

Ahmad MJ, Khan QZ, Ali SM (2016) Use of water tank as tuned liquid damper (TLD) for reinforced concrete (RC) structures. Arab J Sci Eng 41(12):4953-4965

Banerji P (2004) Tuned liquid dampers for control of earthquake response. In: 13th world conference on earthquake engineering, Canada, Paper No. 1666

Bhattacharjee E, Halder L, Sharma RP (2013) An experimental study on tuned liquid damper for mitigation of structural response. Int $\mathbf{J}$ Adv Struct Eng 5(3):1-8

Bigdeli Y, Kim D (2016) Damping effects of the passive control devices on structural vibration control: TMD, TLC and TLCD for varying total masses. KSCE J Civil Eng 20(1):301-308. doi: 10.1007/s12205-015-0365-5

Fujino Y, Sun LM (1993) Vibration control by multiple tuned liquid dampers (MTLDs). J Struct Eng ASCE 119(12):3482-3502 (Paper No. 4069)

Kim YM, You KP, Cho JE, Hong DP (2006) The vibration performance experiment of tuned liquid damper and tuned liquid column damper. J Mech Sci Technol 20(6):795-805

Lee SK, Park EC, Min KW, Chung L, Park JH (2007) Real-time hybrid shaking table testing method for the performance evaluation of a tuned liquid damper controlling seismic response of building structures. J Sound Vib 302:596-612

Mondal J, Nimmala H, Abdulla S, Tafreshi R (2014) Tuned liquid damper. In: Proceedings of the 3rd international conference on 
mechanical engineering and mechatronics, Prague, Czech Republic, Paper No.: 68

Roy A, Ghosh A (2012) Design a tuned liquid damper system for seismic vibration control of elevated water tanks. In: Proceedings of the international symposium on engineering under uncertainty: safety assessment and management (ISEUSAM2012), 549-562

Ruiz RO, Lopez-Garcia D, Taflanidis AA (2016) Modeling and experimental validation of a new type of tuned liquid damper. Acta Mech 1-20. doi:10.1007/s00707-015-1536-7

Saha S, Debbarma R (2015) An experimental investigation on dynamic response control of structures using tuned liquid column damper. Int J Eng Technol Manag Appl Sci (IJETMAS) 3:181-187

Samanta A, Banerji P (2008) Structural control using modified tuned liquid dampers. In: The 14th world conference on earthquake engineering, Beijing, China

Tait MJ, Isyumov N, Damatty AAEI (2008) Performance of tuned liquid dampers. J Eng Mech 134(5):417-427

Tamura Y, Fujii K, Ohtsuki T, Wakahara T, Kohsaka R (1995) Effectiveness of tuned liquid dampers under wind excitation. Eng Struct 17(9):609-621 